\title{
SOLDER SPREAD: A CRITERION FOR EVALUATION OF SOLDERING
}

\author{
G. Humpston \\ \& \\ D. M. Jacobson \\ Metallurgical Technology Group \\ GEC Hirst Research Centre \\ Wembley UK
}

\begin{abstract}
Quantitative measurements of the intrinsic spread characteristics of solders used in electronics applications can be carried out by making use of the beneficial properties of gold.
\end{abstract}

$\mathrm{I}$ is well known that some solders flow and spread more readily than others and is widely held that eutectic composition alloys are usually the most fluid, that is they exhibit a relatively high degree of spread $[1,2]$. Indeed, this is one of the main reasons why solders tend to be based on eutectic alloys [3]. Another reason is that solders of eutectic composition transform from liquid to solid at a single temperature rather than over a finite temperature range. The most widely used solder, of the Pb-60wt.\%Sn composition, embodies both of these features. Restricted flow is generally regarded as being indicative of a poor joint, caused by factors such as dewetting, oxidation of the components or the substrate temperature being too low.
High fluidity of molten solders is a desirable property where the filler metal is applied as a slug of wire to one edge of a heated assembly and expected to flow into the joint by capillary action. However, there are other situations where it is both possible and more convenient to sandwich a foil of the solder between the components which are then joined together in an appropriate heating cycle. When this configuration is used, a high degree of solder spread might actually be detrimental to good joint filling because the molten alloy will tend to flow out of the joint. Therefore, there is also a requirement for solders that possess low spread characteristics, even when all surfaces are perfectly clean and wettable by the molten solder. 
To date, there is little published data comparing the spread characteristics of different solders and relating this property to their propensity to fill joints. This dearth of quantitative information can be attributed largely to the lack of a suitable substrate on which to base objective comparisons of solder flow and joint filling. An "ideal" substrate would have to fulfil a number of requirements. In particular it would need to be:

- readily wetted by all molten solders, without the aid of fluxes which might introduce spurious effects;

- essentially inert, from a metallurgical point of view, so that wetting by the solder would neither modify the balance of phases present in the solder, nor its physical characteristics;

- stable against exposure to the atmosphere so that the substrate would have a reasonably long solderability "shelf-life" for carrying out reproducible tests;

- easy and cheap to fabricate to a consistent quality.

Failure to satisfy any of these requirements restricts the relevance of the published data on solder spread beyond the particular combination of materials and processes examined. This study identifies an "ideal" substrate which satisfies all of the above criteria, within certain limits. It then describes how this substrate was used to derive comparative solder spread data for a selection of binary alloy solders, comprising all combinations of the elements bismuth, indium, lead, silver and tin. The spread data is then compared and contrasted and the differences analysed.

A companion article will extend the study to assessing the relationship between solder spread and hermeticity of joints made using solder preforms.

\section{Development of an "Ideal" Substrate}

In order for a molten alloy to wet a metallic substrate in the absence of fluxes, it is generally necessary for the surface of the substrate to be completely free of any non-wettable surface films such as organic residues and oxides. Noble metals such as platinum and gold are unreactive towards ambient atmospheres and to solvents used for degreasing. These metals are therefore solderable even without fluxes being present and, on that account, are suitable candidates for the required solder test substrates. Gold was selected in preference to platinum precisely because it is widely used in flux-free soldering applications [4].

However, gold is highly soluble in most common solders and the resulting alloying alters their metallurgical and physical characteristics $[4,5,6,7]$. An exception to this trend is provided by some of the indium-based solders. These alloys react with gold to form an interfacial layer of the AuIn2 intermetallic compound [4]. Once established, this layer tends to inhibit further interaction between the gold layer and the molten solder, thereby preventing the dissolution of gold by the solder reaching a level where it significantly modifies the metallurgical characteristics of the latter.

One obvious means of limiting the dissolution of gold in solders is to restrict the volume of this metal to a thin surface coating. If this coating is made sufficiently thin, relative to the volume of solder, it will not appreciably affect the characteristics of the solder. The relevant data on maximum concentrations of gold in various solders that will assure compliance with this condition have been published [4]. At the other extreme, there is a minimum limit to the gold coating thickness, namely that which is capable of providing an adequate solderability shelf-life. Data relating gold thickness to shelf-life was not available from the literature and had to be obtained as a preliminary step to this study. This work is described in the following section.

Because the thin gold layer envisaged was considered likely to completely dissolve in most of the molten solders, an underlying metallic layer is required and therefore has to form an essential part of the substrate. The candidate metal would be protected from the atmosphere by the gold overlay, prior to the application of the solder, so that its reactivity with the ambient atmosphere was not a consideration in the choice. However, it is necessary that a clean surface of this metal is readily wetted by molten solders while, at the same time, it is essentially insoluble in these alloys. A $0.1 \mu \mathrm{m}$ thick layer of chromium, applied by sputter-deposition to a glass substrate, has been found by previous experience at the GEC Hirst Research Centre to satisfy this requirement. Once deposited, the chromium layer must be 
immediately coated with gold, without breaking the vacuum, in order to ensure that it does not oxidise.

The adoption of a standard glass substrate of known flatness was deliberate, because surface roughness is known to influence the rate of reaction between solders and substrates $[8,9]$. This is presumably associated in some manner with the increase in surface area that accompanies increasing surface roughness. It was possible to use glass as the bulk substrate, even though it is not wetted by solders, because it is covered with the layer of chromium which is insoluble in most solders. The chromium-on-glass combination also enables any dissolution of the chromium by a solder to be detected visually from the underside of the substrate.

Metals such as nickel, titanium, molybdenum and tungsten, all of which are routinely deposited by vapour phase processes, were considered as possible alternatives to chromium. However, all of these metals react with one or more of the constituents of common solder alloys. Thus, for example, nickel dissolves in silver, titanium in indium and tìn, while tungsten and molybdenum dissolve in molten lead.

Sputtering is frequently chosen for applying thin metallisation layers to substrates because this vapour deposition technique is capable of doing so in a highly controllable and reproducible manner. Moreover, the layers can be deposited with a high density and low porosity, as compared with electroplating. Sputtering is also amenable to multilayer deposition and it offers the possibility of cleaning surfaces by reverse sputtering, or sputter etching, prior to commencing the deposition and so ensures excellent adhesion of the coatings to the base material. These features made sputtering a natural choice as the technique to use for preparing the "ideal" substrates.

\section{Assessment of the Shelf-life Solderability Provided by Thin Gold Coatings}

The following programme of work was undertaken in order to establish the solderability shelf-life characteristics of sputtered gold coatings as a function of their thickness. For comparative purposes, gold coatings ap- plied by wet plating methods were assessed in parallel, because these are widely used in industry, their being highly amenable to mass fabrication.

\section{Experimental Procedure}

The substrates for assessment of the shelf-life of electroplated gold coatings were based on coupons of copper, a metal that is widely used as a substrate for soldered joints. The coupons, which measured $15 \times 10 \times$ $0.15 \mathrm{~mm}$, were chemically cleaned and then immediately electroplated with either $0.1,1$ or $5 \mu \mathrm{m}$ of gold.

Glass specimens with the same surface dimensions, but $1.1 \mathrm{~mm}$ thick, were cut from microscope slides and used as the substrates for the sputtered gold coatings. These were metallised with $0.1 \mu \mathrm{m}$ of sputtered chromium, followed by either 0.1 or $0.3 \mu \mathrm{m}$ of sputtered gold. The chromium is not only readily wettable by the solders but, at the same time, adheres strongly to the glass through the formation of a reactive bond. Chromium also has a high affinity for oxygen and will therefore rapidly oxidise should the gold overcoat not provide a hermetic cover. Oxidation of either the chromium or the copper will manifest itself in dewetting of the solder from the substrates, in the absence of an active flux.

These coated substrates were stored under ambient conditions for varying periods of time, up to one year, before being tested. Triplicate samples were tested in each case.

The widely used $\mathrm{Pb}-60 \mathrm{wt} . \% \mathrm{Sn}$ solder was used for the solderability shelf-life determination, described below. The solder was prepared in approximately $10 \mathrm{~g}$ quantities from $99.999 \%$ purity lead and tin by melting under a shroud of burning hydrogen, followed by a water quench. The ingots were then remelted in high vacuum and again water quenched.

Assessment of solderability was made using a GEC Meniscograph wetting balance which had been adapted for operating inside a vacuum chamber under a base pressure of $1 \times 10^{-6} \mathrm{~Pa}$ [10]. This equipment is illustrated in Plate la and $\mathbf{b}$. A specimen changing mechanism was added to the equipment to enable ten specimens to be tested in series without breaking the vacuum. The Meniscograph operates by lowering a testpiece into a bath of solder to a preset immersion depth. The vertical component of the forces acting on the specimen is measured by the înstrument as a function of time and 


\section{Plate 1a}

The GEC Meniscograph ${ }^{\circledR}$ solderability tester.
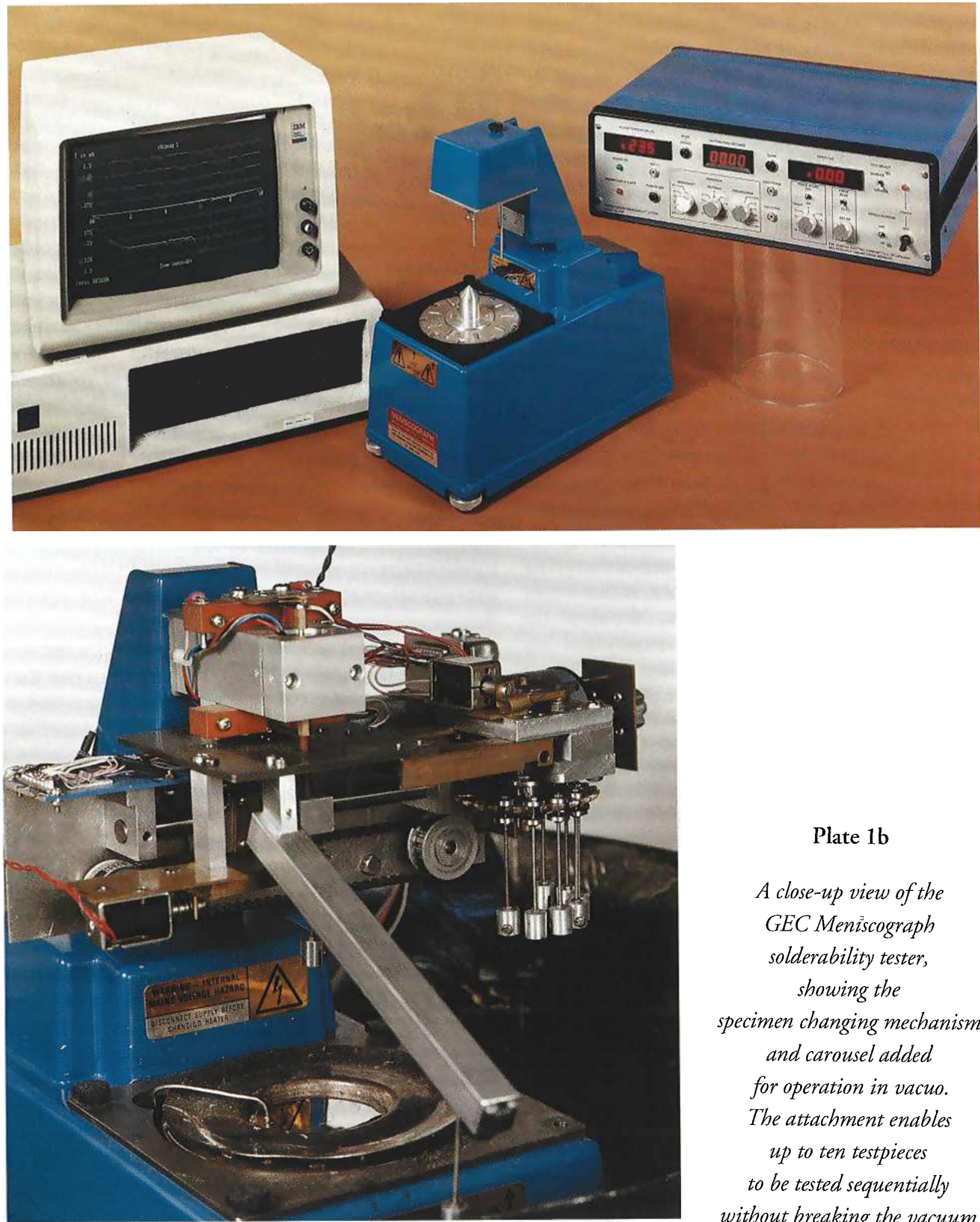

Plate 1b

$A$ close-up view of the GEC Meniscograph solderability tester, showing the specimen changing mechanism and carousel added for operation in vacuo. The attachment enables up to ten testpieces to be tested sequentially without breaking the vacuum. 


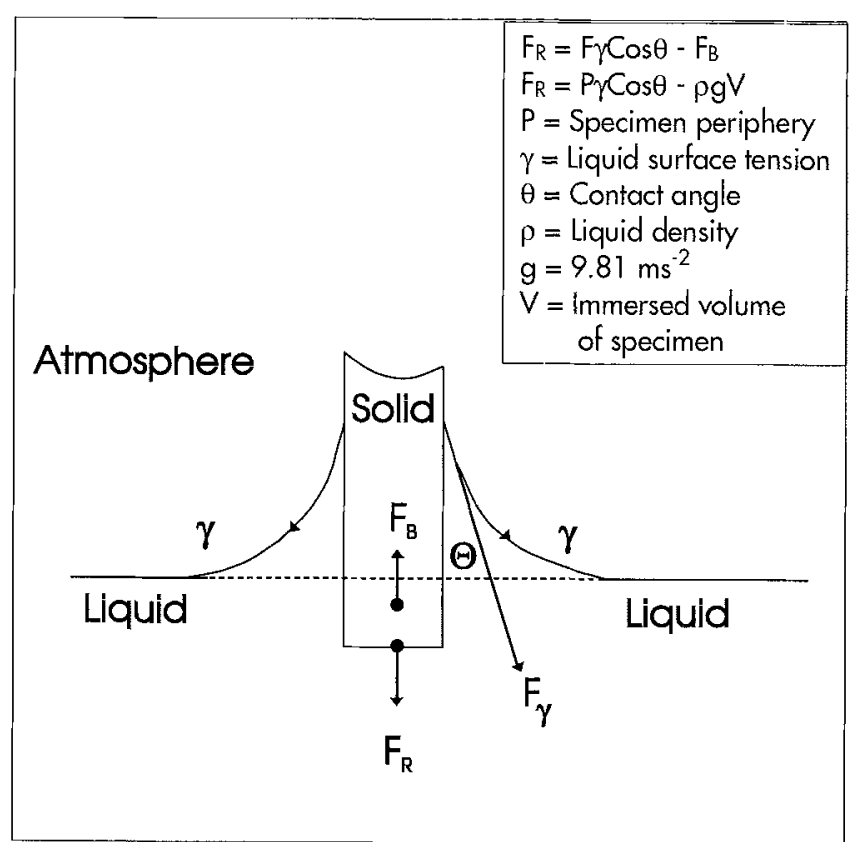

Figure 1

Forces diagram for a solid plate partially immersed in a liquid. The GEC Meniscograph solderability tester dynamically measures the resultant of the buoyancy force $F_{\mathrm{B}}$ and the resolved capillary force $F_{\mathrm{R}}$.

logged on a computer. The measured force is the resultant of the Archimedean buoyancy force and the vertical component of the surface tension force, the latter containing a component due to wetting/non-wetting of the substrate by the solder, as shown in Fig. 1. After the testpiece has been immersed in the solder bath for a set time, the measurement is terminated and the testpiece withdrawn. For the experiments described, the temperature of the solder bath was $233^{\circ} \mathrm{C}$, which is $50^{\circ} \mathrm{C}$ above the melting point of the solder. The speed at which the testpiece was immersed was $20 \mathrm{mms}^{-1}$, the immersion depth was $2 \mathrm{~mm}$ and the time of immersion 100 seconds, which was the maximum setting available on this model of the equipment.

The Meniscograph is well suited to the assessment of the solderability shelf-life of gold coated substrates. In the first place, it provides a quantitative measure of wetting of the substrates by the molten solder. Moreover, gold is highly soluble in molten tin-lead solder, the dissolution rate being typically $1 \mu \mathrm{ms}^{-1}$ [11]. Accordingly, the thin gold coatings on the substrates eval- uated rapidly dissolve into the relatively large volume of solder in the bath and play no further role in the wetting process, which then solely involves either the chromium or copper substrates and the solder. The quantitative measure of solderability obtained therefore is determined by the condition of the underlying substrate.

\section{Results}

The solderability of samples was tested immediately after coating with gold and then at regular intervals over a timespan of a year. The maximum wetting force measured during immersion of the substrates in the molten $\mathrm{Pb}-60 \mathrm{wt} . \% \mathrm{Sn}$ solder for 100 seconds is given in Fig. 2 for the copper with electroplated gold testpieces and in Fig. 3 for the glass with sputtered chromium and gold testpieces.

The maximum wetting force measured on the freshly plated copper coupons was $7.2 \pm 0.7 \mathrm{mN}$ while the slightly higher value of $7.8 \pm 0.8 \mathrm{mN}$ was obtained for freshly prepared sputter-metallised glass slides. In both cases, the maximum wetting force was independent of the thickness of the gold coating.

After storage of the testpieces in ambient conditions, the wetting force was initially unchanged but, after a given period, proceeded to decrease. The time interval before any perceptible degradation in solder-

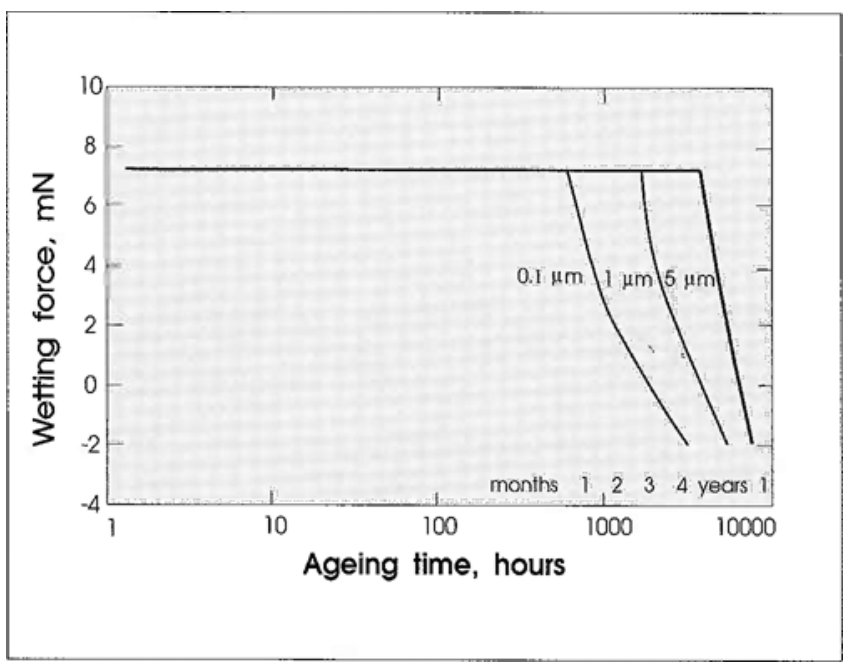

Figure 2

Solderability of copper coupons electroplated with gold, either $0.1,1$ or $5 \mu \mathrm{m}$ thick, as a function of storage time at ambient conditions. 


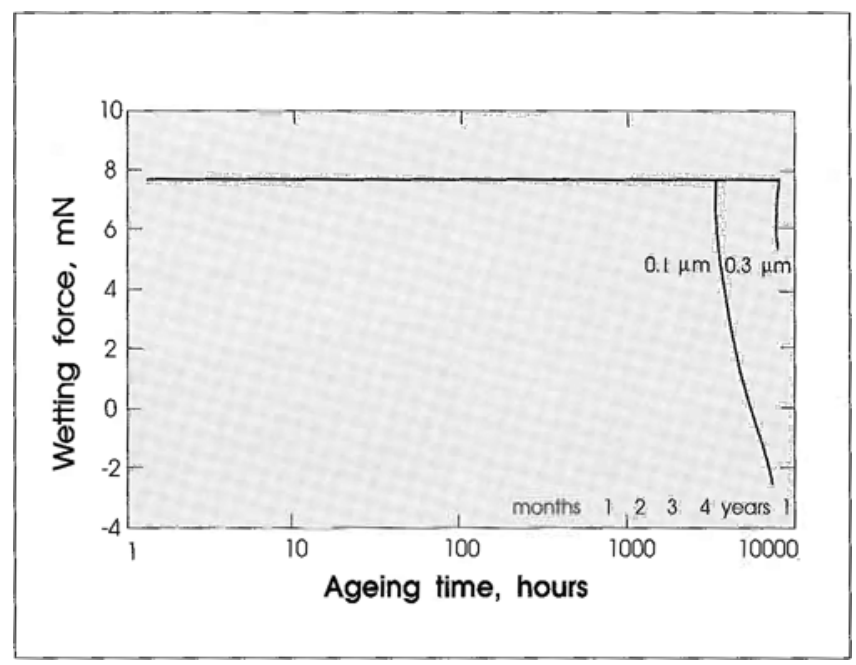

Figure 3

Solderability of glass substrates sputter-metallised with $0.1 \mu \mathrm{m}$ of chromium followed by 0.1 or $0.3 \mu \mathrm{m}$ of gold, as a function of storage time at ambient conditions.

ability occurred was found to depend on the thickness of the gold coating and its method of application. The data are presented in Table 1 . The principal features that are evident are that the thinner the gold coating the shorter is the shelf-life and that an electroplated gold coating consistently has a shorter shelf-life than a sputter-deposited coating of an equivalent thickness.

Table 1

Shelf life provided by thin gold coatings

\begin{tabular}{|c|c|c|}
\hline $\begin{array}{l}\text { Deposition } \\
\text { method }\end{array}$ & $\begin{array}{l}\text { Coating } \\
\text { thickness }\end{array}$ & $\begin{array}{r}\text { Shelf } \\
\text { life }\end{array}$ \\
\hline Electroplating & $0.1 \mu \mathrm{m}$ & 1 month \\
\hline " & $1.0 \mu \mathrm{m}$ & 2 months \\
\hline$"$ & $5.0 \mu \mathrm{m}$ & 4 months \\
\hline Sputtering & $0.1 \mu \mathrm{m}$ & 4 months \\
\hline & $0.3 \mu \mathrm{m}$ & 12 months \\
\hline
\end{tabular}

\section{Discussion}

The high wetting forces obtained for the freshly prepared samples indicate that the testpieces were being wet readily by the molten solder. Indeed, the values ob- tained compare favourably with the maximum theoretical wetting force of $8.9 \mathrm{mN}$, that can be obtained using this combination of materials and test conditions. The thickness of the gold coating has no influence on the maximum wetting force, as was expected from the fact that the gold coating, however thick, is rapidly and completely dissolved by the solder.

With continued exposure to ambient atmosphere, the solderability of all the substrates coated with electroplated gold degraded within the timescale of these aging trials, to the extent that dewetting of the substrate by the solder occurred. This condition was indicated on the Meniscograph by a consistently negative wetting force. It could be concluded that the gold coating failed to protect the underlying metal from oxidising for that length of time. As expected, the thicker the gold coating, the longer was the measured period of time for the degradation to be manifested, because the oxygen diffusion path length is longer.

It is generally recognised that thin gold electroplatings tend to be relatively porous and this was confirmed by these results. In this regard, it is recommended that if tin is used in place of gold, the coating should be at least $5 \mu \mathrm{m}$ thick to maintain good solderability in a normal laboratory environment [12].

By comparison, the sputtered gold coatings provide a significantly longer shelf-life than did the electroplated gold coatings of comparable thickness, as can be seen from the data given in Table 1. This result was not unexpected given that sputtering is generally recognised to produce thin films of higher density and lower porosity than does electroplating [13].

These results enabled a minimum thickness for the gold coatings on the spread test substrates to be defined. A $0.1 \mu \mathrm{m}$ thick layer of gold, applied by sputter deposition, ensures a shelf-life of approximately one month, which was sufficient for carrying out the experimental study. As an additional precaution, the metallised testpieces were stored under vacuum until required.

\section{Evaluation \\ of the "Ideal" Substrate}

For the reasons given above, the substrate that was selected for this study comprised a borosilicate glass plate, approximately $1 \mathrm{~mm}$ thick (microscope slide 
manufactured to BS3836), that was degreased, sputter etched, and then sputter-metallised with a $0.1 \mu \mathrm{m}$ layer of chromium, İmmediately followed by $0.1 \mu \mathrm{m}$ of gold. To assess how closely the properties of this substrate matched those of the "ideal" substrate defined above, the following evaluation was carried out, using the $\mathrm{Pb}-60 \mathrm{wt}$ \% Sn solder.

\section{Wettability}

The dynamic wetting behaviour of molten $\mathrm{Pb}$ $60 \mathrm{wt} . \% \mathrm{Sn}$ solder on the metallised glass substrates was measured both in air, in the presence of a flux containing 1 vol. \% $\mathrm{HCl}$ as the active ingredient, and in vacuo, using the GEC Meniscograph wetting balance. In other respects, the experimental conditions were identical to those used for the shelf-life assessment described above.

A maximum wetting force of $7.8 \mathrm{mN}$ was recorded in vacuo a few seconds after immersing the testpiece into the molten solder, as compared with a value of $8.7 \mathrm{mN}$, when the test was made in air using flux. The rapid attainment of a high and stable wetting force under both conditions indicated that the substrate was being wet readily by the molten solder. The maximum wetting forces measured can be compared with the maximum theoretically attainable force of $8.9 \mathrm{mN}$. Using this figure, it was calculated that the measured wetting forces corresponded to contact angles of $27^{\circ}$ and $12^{\circ}$, for the testpieces tested in vacuum and in air using flux, respectively. The poorer solder wetting of the substrate in vacuo, without the aid of a flux, arises from the fact that a vacuum is incapable of reducing the oxide film that will be present on the surface of the molten solder. Indeed, virtually identical values of contact angle are measured if the test is made in air but with a "non-activated" (i.e. less aggressive) flux applied to the testpiece [14].

\section{Extent of Solder/ \\ Substrate Interactions}

In the experiments of solder spread described below, the solder foils used were $50 \mu \mathrm{m}$ thick, which is typical of the solder foils used in the electronics industry. A $50 \mu \mathrm{m}$ thick foil represents a reasonable compromise between cost of the material, cost of fabrication and ease of handling. When a foil of this thickness is placed on a substrate coated with a $0.1 \mu \mathrm{m}$ thick gold metallisation and proceeds to totally dissolves it, the resulting concentration of gold will be approximately $0.4 \mathrm{wt} . \%$, assuming a typical solder density of $10 \times 10^{3} \mathrm{kgm}^{-3}$ and that the solder does not spread. This is well below the level at which the intermetallic compound $\mathrm{AuSn}_{4}$ will form as a primary phase in lead-tin solders and indeed in the other tin-based alloys used in this study [4].

As the solder spreads, the situation will be reached where significant concentrations of gold are accumulated by the advancing solder front. By referring to the appropriate constitutional diagram, it is possible to calculate the limit of spread for the solder alloy of interest at which the concentration of gold becomes sufficient to form a gold-based intermetallic phase on solidification. Gold concentrations below this level do not have a significant effect on the spread characteristics of molten solders [15]. The limiting values, where known and relevant, have been marked on Fig. 4, which depicts the relationship between solder spread and gold concentration, for a $1.4 \mathrm{~mm}^{3}$ volume of solder (corresponding to a preform $6 \mathrm{~mm}$ in diameter and $50 \mu \mathrm{m}$

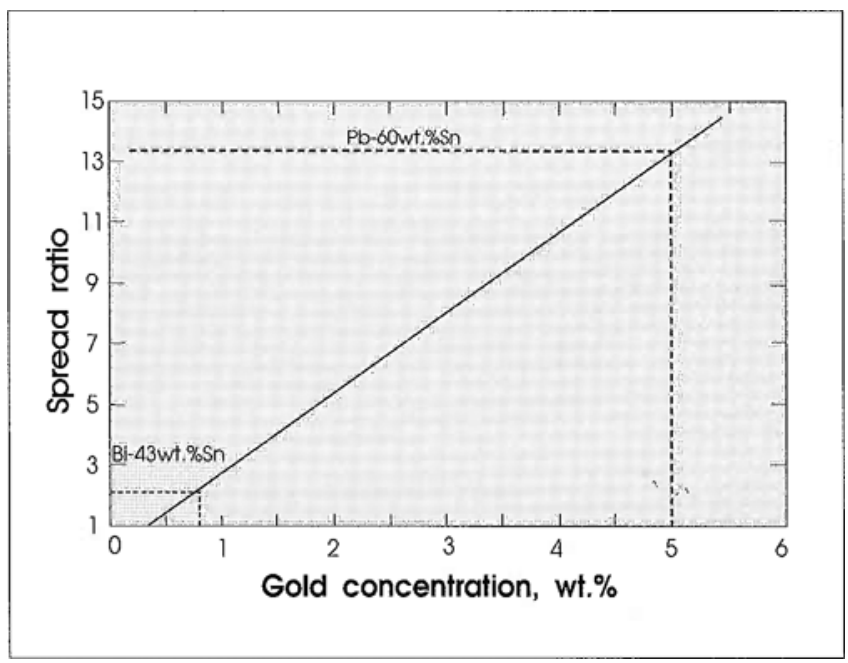

Figure 4

Calculated concentration of gold as a function of solder spread ratio, assuming that the all of the $0.1 \mu \mathrm{m}$ thick gold coating dissolves and is uniformly distributed throughout the volume of the molten solder. 
Table 2

Selected properties of the solder alloys investigated

\begin{tabular}{|c|c|c|c|}
\hline $\begin{array}{l}\text { Solder composition, } \\
\text { wt. } \%\end{array}$ & melting point, & $\begin{array}{l}\text { wt. } \% \text { of gold to form } \\
\text { a new primary phase }\end{array}$ & $\begin{array}{l}\text { compliance as } \\
\text { a thin foil }\end{array}$ \\
\hline $\mathrm{Ag}-97 \mathrm{Bi}$ & 262 & approx. 50 & brittle \\
\hline $\mathrm{Ag}-97 \mathrm{In}$ & 141 & $*$ & ductile \\
\hline $\mathrm{Ag}-97 \mathrm{~Pb}$ & 304 & approx. 20 & ductile \\
\hline $\mathrm{Ag}-96 \mathrm{Sn}$ & 232 & 10 & ductile \\
\hline $\mathrm{Bi}-33 \mathrm{In}$ & 110 & - & brittle \\
\hline $\mathrm{Bi}-44 \mathrm{~Pb}$ & 125 & - & ductile \\
\hline $\mathrm{Bi}-43 \mathrm{Sn}$ & 139 & 0.8 & ductile \\
\hline $\mathrm{In}-50 \mathrm{~Pb}$ & 180 & 0.1 & ductile \\
\hline In-48Sn & 117 & $*$ & ductile \\
\hline $\mathrm{Pb}-60 \mathrm{Sn}$ & 183 & 5 & ductile \\
\hline \multicolumn{4}{|c|}{$\begin{array}{l}\text { These alloys react with gold to form a layer of AuIn } 2 \text { that acts as a barrier layer to } \\
\text { further dissolution of gold into the molten solder and, thereby, to the formation of gold } \\
\text { containing primary phases on solidification of the solder }\end{array}$} \\
\hline \multicolumn{4}{|c|}{$\begin{array}{l}\text { Insufficient phase diagram data is available for these systems to allow the calculation } \\
\text { to be made }\end{array}$} \\
\hline \multicolumn{4}{|c|}{$\begin{array}{l}\text { The In- } 50 \mathrm{wt} . \% \mathrm{~Pb} \text { alloy is non-eutectic. The solidus temperature is } 180^{\circ} \mathrm{C} \text { and the liquidus } \\
\text { temperature } 220^{\circ} \mathrm{C}\end{array}$} \\
\hline
\end{tabular}

thick), Corresponding data for all of the solders, where known, are given in Table 2.

Clearly, when this limiting concentration is exceeded the substrate can no longer be regarded as "ideal", in the sense in which this term has been defined here.

\section{Shelf-life}

The shelf-life of a $0.1 \mu \mathrm{m}$ chromium layer on glass that is covered by a $0.1 \mu \mathrm{m}$ thick layer of gold, both applied by sputter-deposition, has been shown to be one month in ambient conditions, as stated in the third section.

\section{Ease and \\ Reproducibility of Fabrication}

Samples of the substrate described can be readily prepared in a highly reproducible manner, with the thickness of the sputter-metallisations controlled to within typically $\pm 5 \%[13]$.

\section{Overall \\ Assessment}

Based on the results obtained with $\mathrm{Pb}-60 \mathrm{wt} . \% \mathrm{Sn}$ solder and within the limitations noted above, the glass substrate sputter-coated with $0.1 \mu \mathrm{m}$ layers of chromium and gold, conform to the requirements of a test vehicle for comparative solder flow and joint filling assessments. Departures from "ideal." behaviour of the substrates in combination with other solders that were appraised are noted in conjunction with the solder spread tests described below.

\section{Solder Spread as a Function of Temperature}

Having demonstrated the suitability of the substrate under defined conditions, work proceeded to measure solder spread as a function of temperature for a selection of solders.

The solders investigated were binary alloys, based on all combinations of the elements bismuth, indium, lead, silver and tin. The alloy compositions used in the study and their melting points are listed in Table 2 .

Also included in this table are values, calculated from alloy constitutional data, for the minimum concentration of gold in the solders that will result in the formation of a gold-containing primary phase on solidification of the alloy.

Because the appropriate alloy constitutional data were not available for all of the solders considered, speculative values have been derived for the $\mathrm{Ag}$ 97wt.\%Bi and $\mathrm{Ag}-97 \mathrm{wt} . \% \mathrm{~Pb}$ solders.

These values, taken in conjunction with the data in Fig. 4 , were used to define the limits of validity of the solder spread tests for the indivildual solders. 


\section{Experimental}

\section{Procedures}

Small ingots of each of the solder alloys was prepared in the manner described above. These were subsequently cold-rolled to produce thin ductile foils approximately $50 \mu \mathrm{m}$ thick. The Ag-97wt.\%Bi, Bi-33wt.\%In and Bi$43 \mathrm{wt} . \% \mathrm{Sn}$ solders proved too brittle to reduce to foils by this method. Foils of these alloys were instead produced by the chill-block melt-spinning technique. This process involves forcing a molten charge through a slot onto a rapidly spinning, water cooled, copper wheel. The high rate of heat extraction obtained by this method causes the molten alloy to solidify almost instantaneously on striking the wheel, resulting in the formation of a thin strip of the solder alloy with a fine microstructure. By controlling the casting conditions, it is possible to produce the strip directly to the desired thickness. The $\mathrm{Bi}-43 \mathrm{wt} . \% \mathrm{Sn}$ alloy is reasonably ductile when prepared in this manner.

Discs of the various solders, measuring $6 \pm 0.1 \mathrm{~mm}$ diameter, were stamped out of the foils and one disc placed centrally on glass substrates up to $25 \mathrm{~mm}$ x $25 \mathrm{~mm}$ in area, that had been sputter-coated with thin chromium and gold layers. The testpieces were loaded into a silica tube, which was evacuated to a pressure of $1 \times 10^{-4} \mathrm{~Pa}$, and the entire assembly then inserted into a furnace that had been preheated to the requisite temperature. The temperature of the solder was monitored continuously during the heating cycle by a calibrated thermocouple in contact with the centre of the solder disc. The testpieces were maintained at the set temperature for one hour, after which the furnace was withdrawn to produce rapid cooling to below the solidus temperature of the solder.

Following the heating cycle, the total area of the substrate over which the solder had spread was measured using an Optomax V Image Analysis System. The testpieces were viewed on this instrument at a magnification of $\times 5$, giving an effective area resolution of $300 \mu \mathrm{m}^{2}$; The spread measurement was normalised to a spread factor, being the ratio of the area of solder spread to the original area of the solder disc $\left(28 \mathrm{~mm}^{2}\right)$. Thus, if a solder did not spread at all, the spread ratio is one, whereas if a solder flowed to cover an area of $280 \mathrm{~mm}^{2}$, the spread ratio is ten. A spread ratio of 14 was the test limit, defined by the area of the largest substrates.

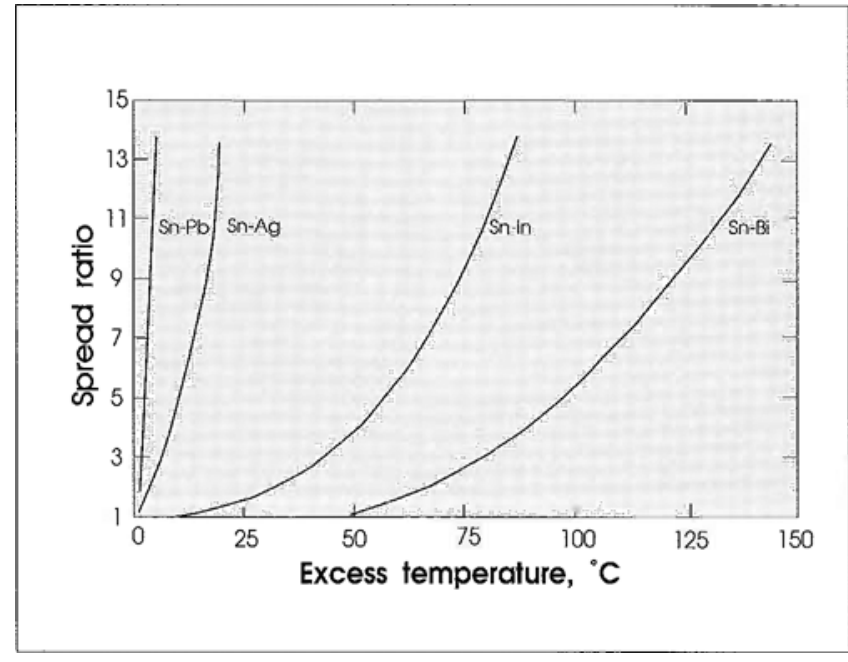

Figure 5

Spread characteristics of binary tin-based solder alloys as a function of excess temperature above the melting point.

\section{Results}

The measured spread factors of eight common industrial solders on the notionally "ideal" substrate, are presented in Figs. 5-9. To facilitate comparison of the data, the scales used in these figures are the same and each spread curve has been presented twice so that there

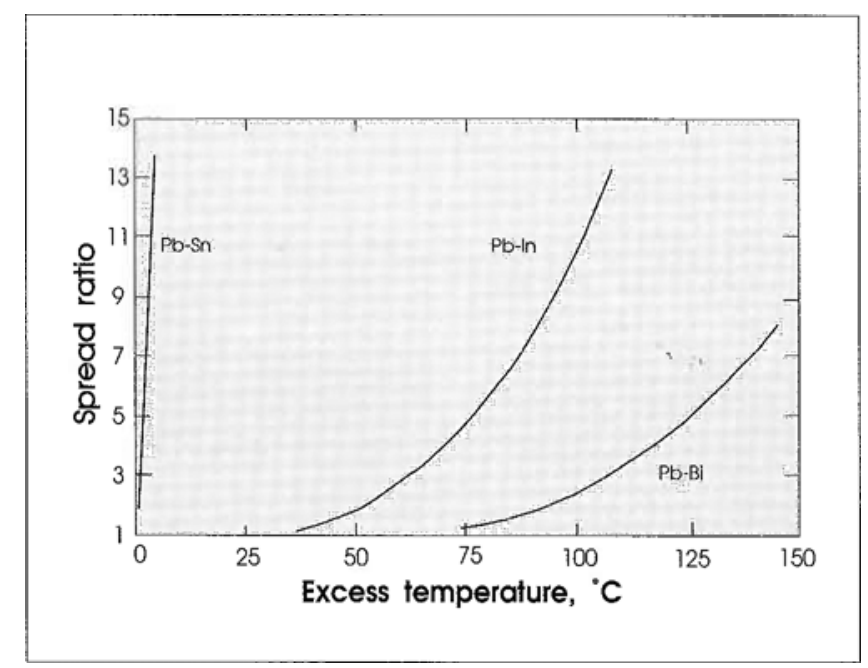

Figure 6

Spread characteristics of binary lead-based solder alloys as a function of excess temperature above the melting point. 


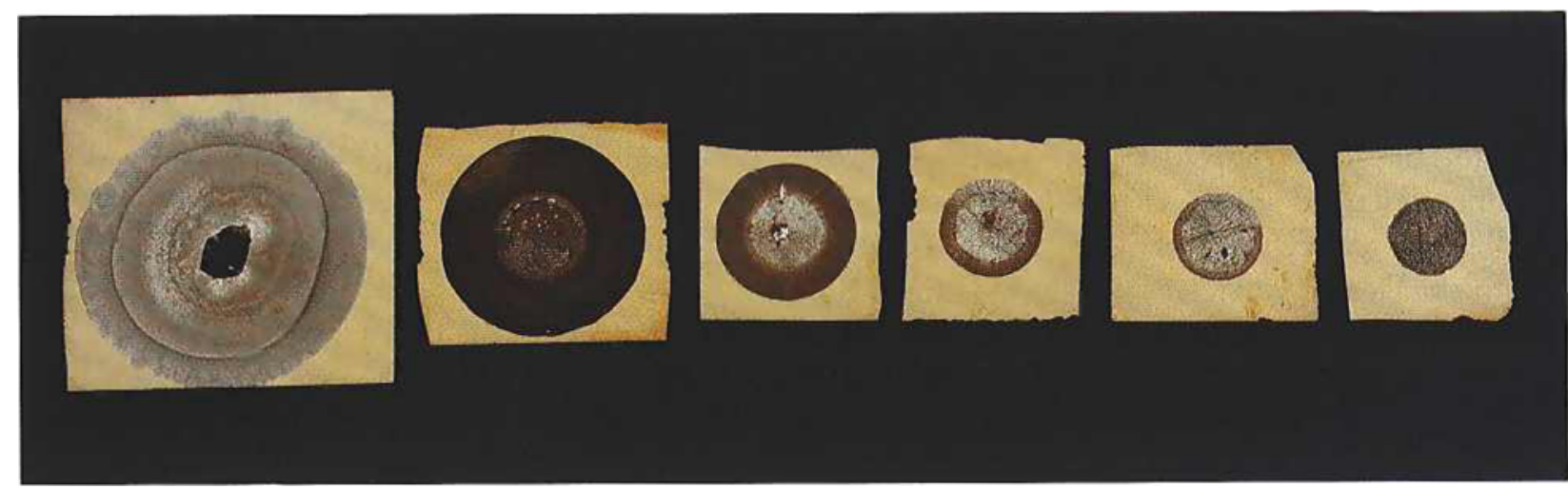

Plate 2

A typical spread test sequence, showing solder spread increasing as a function of temperature. The solder in this case is $\mathrm{Ag}-97 \mathrm{wt} . \%$ In.

The apparent contrast variation between the solidified solder pools is an artefact of the photography, arising from the high reflectivity of the gold-coated substrates.

exists a complete family of spread curves for each of the five elements common to the solders investigated. Typically five spread tests were used to determine each curve, as exemplified by the sequence for the Ag97wt.\%In solder illustrated in Plate 2.

In every case there is a trend towards increased spread the higher the excess temperature above the melting point of the solder at which the test is conducted. The relationship between solder spread and excess temperature is exponential in character. By comparing the spread curves it is possible to rank the constituent elements in order of their tendency to flow over the substrate, namely: tin > lead $>$ silver $>$ indium $>$ bismuth. This order is also maintained within each family of solders, as can be seen from Table 3:

It should be noted that no experimental data was obtained for the In $-50 \mathrm{wt}, \% \mathrm{~Pb}$ solder above $300^{\circ} \mathrm{C}$ nor for the $\mathrm{Ag}-97 \mathrm{wt} . \% \mathrm{~Pb}$ solder at any temperature. This is because at test temperatures above $300^{\circ} \mathrm{C}$, significant volatilisation of the lead occurred from these alloys, as ascertained from analysis of the grey deposit that condensed on the walls of the silica tube at the mouth of the furnace. This is to be expected given the high vapour pressure of lead at these temperatures, coupled with the low background pressure in the vacuum furnace [16]. The volatilisation could be suppressed by performing the spread test in argon at atmospheric pressure. However, the presence of the
Table 3

Excess temperature above the melting point of each solder required to achieve a spread ratio of 5

\begin{tabular}{l|rrrrr|}
\hline & \multicolumn{5}{|c|}{ Element A } \\
Element B & Tin & Lead & Silver & Indium & Bismuth \\
\hline Tin & - & 1 & 9 & 54 & 92 \\
Lead & 1 & - & $*$ & 76 & 126 \\
Silver & 9 & $*$ & - & 122 & + \\
Indium & 54 & 76 & 122 & - & 165 \\
Bismuth & 92 & 126 & + & 165 & \\
& & & & & \\
* Lead volatilises at temperatures above $300^{\circ} \mathrm{C}$ in vacuum. \\
The melting point of Ag- $97 \mathrm{wt} . \% \mathrm{~Pb}$ at $304{ }^{\circ} \mathrm{C}$ is therefore to \\
high to enable measurements of spread to be made in vacuum. \\
+ Bismuth dissolves chromium at temperatures above $265^{\circ} \mathrm{C}$. \\
Accordingly, the molten solder then dewets from the exposed \\
glass substrate.
\end{tabular}
atmosphere signnificantly altered the spread characteristics of the solders and therefore this approach was not pursued.

No data are presented for the Ag$97 \mathrm{wt} \% \mathrm{Bi}$ solder. This is because this solder partly dewets from the substrate due to reaction with the chromium, so that the substrate loses its "ideal" characteristics. The reaction arises from the fact that the Ag97wt.\%Bi solder melts at $262^{\circ} \mathrm{C}$, which is close to the temperature of 


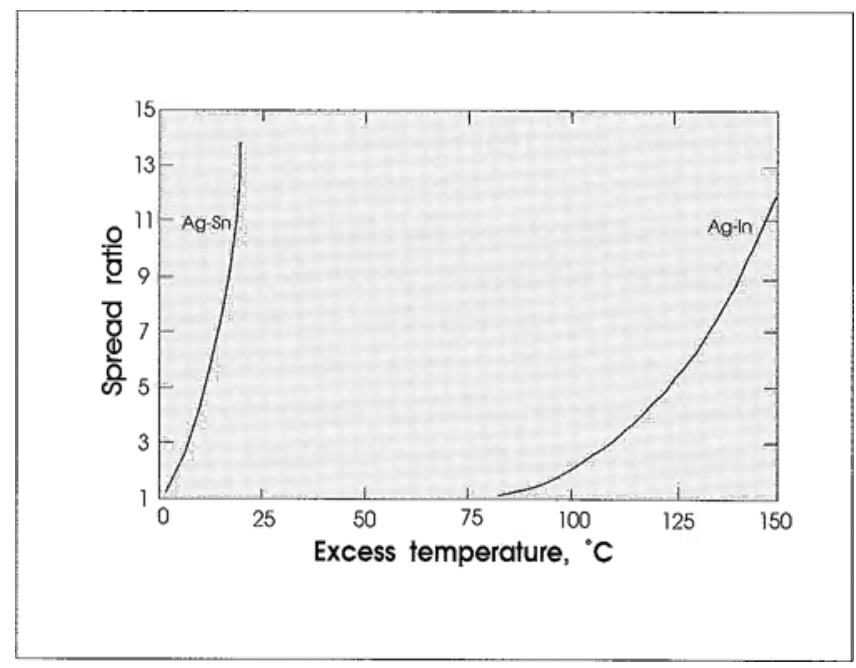

Figure 7

Spread characteristics of binary silver-based solder alloys as a function of excess temperature above the melting point.

$268^{\circ} \mathrm{C}$ at which bismuth enters into eutectic equilibrium with chromium. However, the limited experimental data obtained using the $\mathrm{Ag}-97 \mathrm{wt} . \% \mathrm{Bi}$ alloy would suggest that the area over which dewetting takes place increases only gradually with excess temperature. This

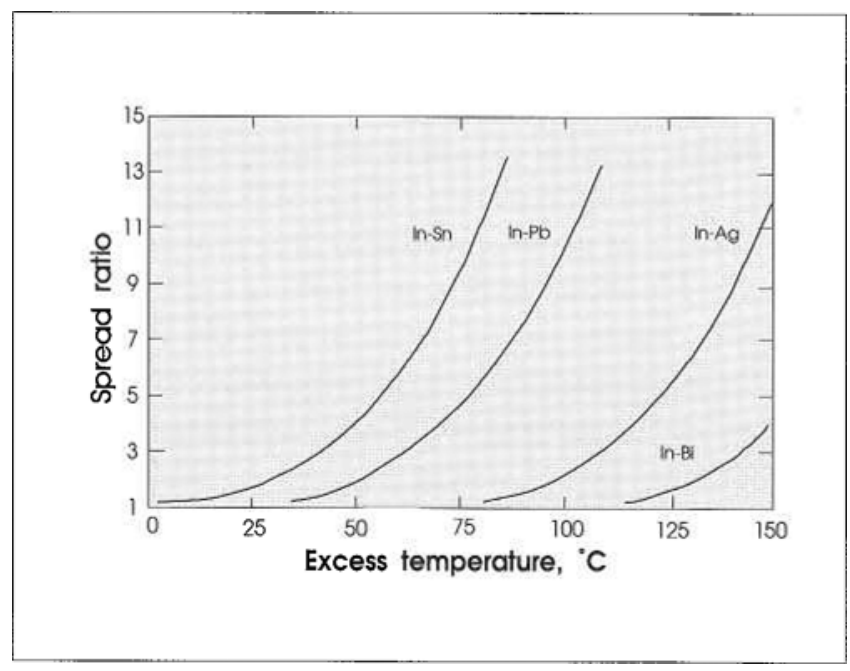

Figure 8

Spread characteristics of binary indium-based solder alloys as a function of excess temperature above the melting point. observation can be interpreted as an indication that the flow characteristi"cs of the Ag- $97 \mathrm{wt} . \% \mathrm{Bi}$ solder are poor, which is largely consistent with the results obtained for the other bismuth containing solders. The other solders containing bismuth that were assessed melt at considerably lower temperatures and therefore no manifestation of a reaction with the chromium was observed.

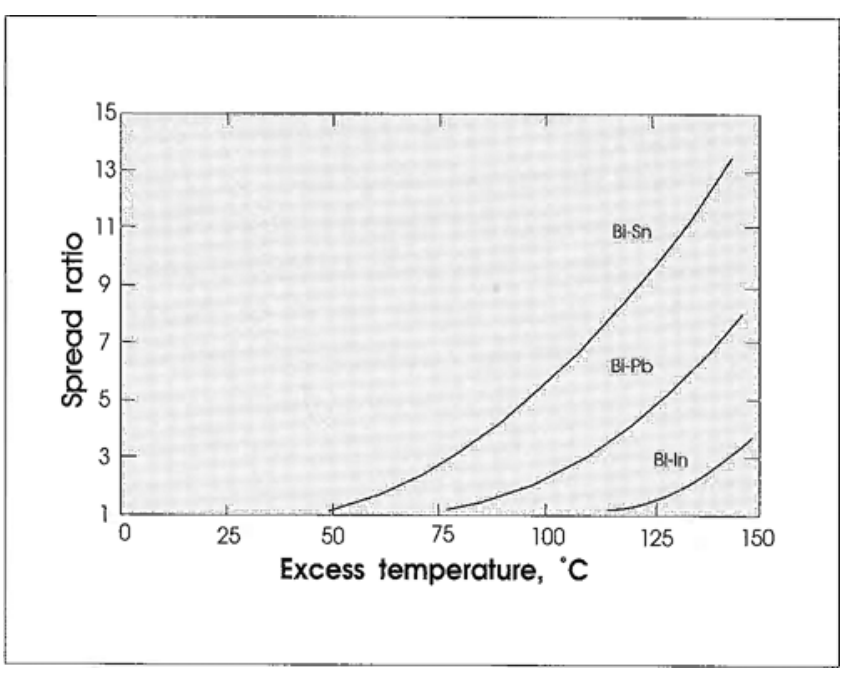

Figure 9

Spread characteristics of binary bismuth-based solder alloys as a function of excess temperature above the melting point.

\section{Discussion}

It is evident from the results presented in Figs. 5-9 that the spread of a molten solder as a function of temperature is highly dependent on the elements which comprise the solder alloy. The conventional wisdom that an excess temperature above the melting point of $50^{\circ} \mathrm{C}$ provides a good compromise between the fluidity of a solder and its reactivity with both the substrate and atmosphere [17] îs clearly an erroneous generalisation for the majority of the solder compositions studied. This fact is highlighted by the data given in Table 3 which is the excess temperature above the melting point of a solder required to obtain a spread ratio of five. The measured values range from approximately $1^{\circ} \mathrm{C}$ for the $\mathrm{Pb}-60 \mathrm{wt} . \% \mathrm{Sn}$ solder to $165^{\circ} \mathrm{C}$ for the $\mathrm{Bi}-33 \mathrm{wt} . \% \mathrm{In}$ eutectic composition alloy. 
Some elements are clearly more effective at promoting flow than others. In particular, solders containing tin all exhibit consistently high spread, whereas those based on bismuth do not spread to any significant extent at excess temperatures above the melting point of less than $100^{\circ} \mathrm{C}$. Detailed analysis of the results showed that the rankingorder in terms of spread at a given excess temperature above the melting point is: tin > lead > silver $>$ indium $>$ bismuth. This ranking sequence is maintained irrespective of the second constituent of the solder. However, it was not found possible to extract a specific weighting factor for the individual elements in respect of their promotion of spread.

One major reason for there being no direct quantitatrve relationship between the elemental composition and spread of a solder is that not all of the solders are simple binary eutectics between the pute elements. Indeed, of the common alloys for which spread data was obtained, only the Bi-43wt.\%Sin and $\mathrm{Pb}-60 \mathrm{wt} . \% \mathrm{Sn}$ solders fit this description. All of the other alloys involve either one or two intermetallic compounds or are wholly non-eutectic, such as In-50wt. $\% \mathrm{~Pb}$.

The importance of this consideration is well illustrated by comparing the spread characteristics of the In-48wt. $\% \mathrm{Sn}$ solder with those of pure indium and pure tin. The relevant curves are shown in Fig. 10. The spread characteristics of the In- $48 \mathrm{wt} \%$ Sn solder do not lie between those of indium and tin, as might be ex-

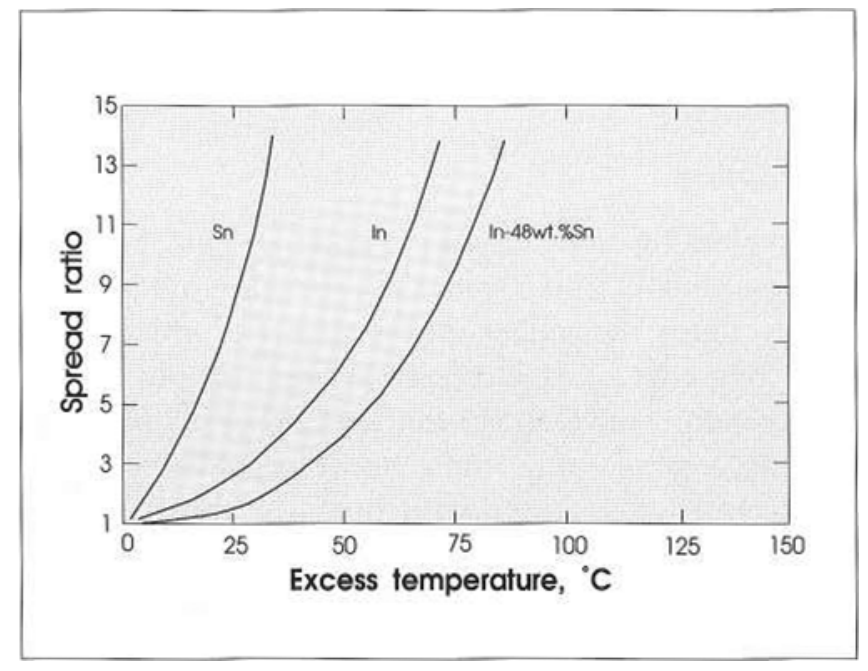

Figure 10

Spread characteristics of pure indium, tin and
the In-48wt. \% Sn solder alloy as a function
of the excess temperature above the melting point.

pected if a simple relationship applied between solder composition and spread. Instead the spread of the alloy is actually inferior to that of either of the rwo elements, which would seem to confound the accepted wisdom that eutectic solders have high fluidity compared with their constituent elements.

It is indeed surprising that the ranking order of spread promoted by the various elements is so consistent, given the very different manner in which the various solders react with the substrate. This point is highlighted by contrasting the manner in which the $\mathrm{Pb}-60 \mathrm{wt} \% \mathrm{Sn}, \mathrm{In}-50 \mathrm{wr} . \% \mathrm{~Pb}$ and In-48wt.\%Sn solders react with gold coated substrates. The $\mathrm{Pb}-60 \mathrm{wt} . \% \mathrm{Sn}$ alloy can dissolve up to $5 \mathrm{wt} \%$ of gold before there is any significant change to its spread characteristics, wher molten [4], whereas the dissolution of any gold into the In $50 \mathrm{wt} . \% \mathrm{~Pb}$ solder results in the solder becoming pasty through the formation of precipitates of the intermetallic compound AuIn2 [18]. The reaction of the In-48wt.\%Sn solder with gold is again very different with the establishment of an interfacial layer of AuInz, between the molten solder and the gold coating [4]. Once established this interfacial layer acts as an effective barrier between the indium and the gold because dissolution of the gold then appears to cease [4].

Despite such differences, the spread data scattered in the literature indicates that the ranking order of: tin $>$ lead $>$ silver $>$ indium $>$ bismuth for solder spread is generally observed. This applies not only to binary alloys but also to ternary and quaternary alloys, whẹcher or not the tests are performed in vacuo or in air using mild fluxes, and for a varety of substrates including copper, tin and mild steel $[19,20,21,22]$. However $r_{z}$ it is to be noted that when spread tests are performed in air using a highly activated flux, the ranking order is altered [20]. This feature clearly demonstrates the interfering effect fluxes can have. Hence the importance of avoiding fluxes when attempting to obtain basic data on solder properties.

\section{Conclusions}

Gold coatings have a vital role to play in promoting soldering in the absence of fluxes. The chemical inertness and ease of deposition of gold as a high integrity coating have been exploited in devising a suitable sub- 
strate for making a quantitative assessment of the spread of different solders.

This substrate comprises $0.1 \mu \mathrm{m}$ thick layers of chromium and gold sequentially applied by sputter-deposition to a borosilicate glass substrate. A $0.1 \mu \mathrm{m}$ layer of gold has been shown to protect the underlying metal from the atmosphere under ambient conditions and preserving its solderability for up to one month. The substrate is readily wetted by molten solders, does not significantly modify the metallurgical characteristics of most common solder alloys and is readily fabricated.

Departures from this "ideal" behaviour were only seen to occur at high spread ratios, where the pĩck-up of gold can become significant, and with one of the solders evaluated, namely $\mathrm{Ag}-97 \mathrm{wt} . \% \mathrm{Bi}$, that was found to react with the chromium underlayer to cause dewetting. The spread of nine binary solders comprising combinations of the elements bismuth, indium, lead, silver and tin, determined in vacuo, on the specified substrate have been compared and the following trends identified:

- The spread of solders increases at an accelerating rate as the excess temperature above the melting point of the solder increases.

- Some of the solders spread more readily than others. A consistent ranking order of elements in terms of solder spread has been established, viz. tin $>$ lead $>$ silver $>$ indium $>$ bismuth. This pattern is consistent with the data scattered in the literature and is also applicable to other substrates.

\section{Abstract}

Solder spread is commonly used as a yardstick for assessing the quality of a soldered joint. However, the spread of a molten alloy is a function not only of the temperature and cleanliness of the joint surfaces, but also of the solder composition.

The beneficial properties of gold have been used to devise a test substrate for quantitatively measuring the intrinsic spread characteristics of nine solders comprising binary combinations of bismuth, indium, lead, silver and tin. The measurements were carried out in vacuum without fluxes, to avoid extraneous effects. It was ascertained that the constituents promote solder spread in a ranking order:

$$
\text { tin }>\text { lead }>\text { silver }>\text { indium }>\text { bismuth }
$$

This finding is consistent with other published data.

\section{Acknowledgements}

The assistance of Miss L. Lanier, of Université des Sciences et Techniques de Lille-Flandres-Artois, is gratefully acknowledged in obtaining the data presented in Figs. 2 and 3.

The World Gold Council and The General Electric Company plc are acknowledged for their support of this study.

\section{REFERENCES}

1 G.L. Bailey and H.C. Watkins, 'The flow of liquid metals on solid metal surfaces and its relationship to soldering, brazing and hot-dip coating', J. Inst. Met., 1951, 80, 57-76

2 K.S. Raman, A.A. Krishnan and W. Ramachandran, 'The spreading characteristics of tin-lead solders on copper', Ind. J. Tech., 1963, 1, 471

3 C.J. Thwaites, 'The attainment of reliability in modern soldering techniques for electronic assemblies', Int. Met. Rev., 1972, 17(9), 149-174

4 D.M. Jacobson and G Humpston, 'Gold coatings for fluxless soldering', Gold Bull, 1989, 22, 9-18

5 R. Duckett and M.L. Ackroyd, 'The influence of solder composition on the embrittlement of softsoldered gold coatings'. Electroplat. Met. Finish., 1976, 29(5), 13-20

6 D.S. Evans and A. Prince, 'The effect of gold on the Pb-1.5\%Ag-1\%Sn solder', Mat. Res. Bull., 1982, $17,681-687$

7 F.G. Yost, 'Soldering to gold films", Gold Bull., 1977, 10, 2-7 
8 L.J. Rickabaugh, "The effect of thin film deposition angle and substrate surface roughness on film dissolution in molten $60 S n-40 P b$ solder', Electrocomponent Science and Technology, 1977, 4, 43-46

9 R.H. Minetti and L.J. Rickabaugh, Solder dissolution rates of evaporated and sputtered Ti-Pd-Au and NiCr-Au thin films', Proc. 27th Electronic components Conf., Arlington, Virginia, 16-17 May, 1977, 212-219

10 D.M. Jacobson and I. Gunter, 'The Meniscograph Solderability Tester: Adaptation to Vacuum Soldering', GEC Review, 1990, 6(2), in press

11 W.G. Bader, 'Dissolution of $A u, A g, P t, C u$ and $N i$ in a molten tin-lead solder'. Welding J. Res. Suppl., $1969,48,551 S-557 S$

12 C.A. Mackay, 'Surface finishes and their solderability' International Tin Research Institute, Publication No 561, 1979

13 N.S. Platakis and L. Missel, 'Wet and Vacuum Coating Processes,' Metal Finishing, 1978, 76 (5), 93-97; ibid. (6), 65-69; ibid. (7), 50-54; ibid. (8), 56-61; ibid. (9), 65-68

14 A.J, Mayhew and G.R. Wicks, 'Solderability and contact angle', Proc. Int. electronic packaging and production conf., Brighton, England, 19-21 October, 1971

15 R.N, Wild, Effects of gold on the properties of solders'. IBM Federal Systems Div., Owego, Rep. No. 67-825-2157, January 1968

16 C.J. Smithells, 'Metals Reference Book', (5th ed.), London, 1976, 232

17 H.H. Manko, 'Solders and soldering', (2nd ed.), New York, 1979, 56

18 M.M. Karnowsky and F.G. Yost, 'The Au-In-Pb system: The AuIn ${ }_{2}-I n-P b$ portion', Met. Trans., 1976, 7A, 1149-1156

19 C.F. Knight and K.T. Harrison, 'Development of zinc based solders', Proc. 4th British Association for Brazing and Soldering conf., London, 1-3 November, 1983

20 R.N. Wild, Properties of some low melting point fusible solder alloys, IBM Federal Systems Div., Owego, Rep. No. 71Z000408, October 1971

21 D.H. Brewer, 'Solders for thick gold plating', Welding J. Res. Suppl., 1970, 49, 465-470

22 W.A. Mulholland and D.L. Willyard, Soldering to thin film bybrid microcircuits;" Welding J. Res. Suppl., 1974, 53, 466-474 